\title{
Instituto Clodomiro Picado: cincuenta años de contribuciones científicas
}

\section{Clodomiro Picado Institute: fifty years of scientific contributions}

\author{
Mahmood Sasa Marín \\ Universidad de Costa Rica, Instituto Clodomiro Picado; San José, Costa Rica. \\ msasamarin@gmail.com \\ https://orcid.org/0000-0003-0118-5142
}

Referencia/ reference:

Sasa, M. (2020). Instituto Clodomiro Picado: cincuenta años de contribuciones científicas. Yulök Revista de Innovación Académica, 4(2).10-28. https://doi.org/10.47633/yulk.v4i2.316

\section{Resumen}

El accidente ofídico es un importante problema de salud que posee múltiples dimensiones, por lo que su abordaje debe ser integral. A partir de una iniciativa país, el problema del ofidismo en Costa Rica es tratado desde una universidad pública en la figura del Instituto Clodomiro Picado (ICP). La búsqueda de soluciones al problema local ha tenido importantes repercusiones a nivel regional y global, por lo que la labor del ICP es considerada como un ejemplo exitoso que ha logrado metas de gran trascendencia en los planos científico, productivo y de extensión. El éxito del ICP va más allá de las publicaciones científicas o del número de frascos de antiveneno producido, lo cual se evidencia en la gran cantidad de personas que recuperan su salud y sus propias historias. Ese logro es producto del liderazgo que generan individuos de nuestra propia comunidad académica, el enfoque en la generación de conocimiento científico de manera integral, donde se respeta la iniciativa y creatividad individual. pero enmarcada en los principios de colaboración y servicio.

Palabras clave: Instituto Clodomiro Picado, Accidente Ofídico, Antiveneno, 50 Años de Trayectoria Científica.

\section{Abstract}

The Ophidic Accidents is an important health problem that has multiple dimensions, so its approach must be comprehensive. As a result of a country initiative, the problem of of idiocy in Costa Rica is being addressed by a public university in the form of the Clodomiro Picado Institute (ICP). The search for solutions to the local problem has had important repercussions at the regional and global level, and the work of the ICP is considered a successful example that has achieved goals of great importance in the scientific, productive and outreach fields. The success of ICP goes beyond the scientific publications or the number of vials of antivenin produced, which is evidenced by the large number of people who recover their health and their own stories. That achievement is the product of the leadership generated by individuals from our own academic community, the focus on the generation of scientific knowledge in a comprehensive manner, where individual initiative and creativity is respected. but framed in the principles of collaboration and service.

Keywords: Clodomiro Picado Institute, Ophidic Accident, Antivenom, 50 Years of Scientific Trajectory. 


\section{Envenenamiento ofídico y su abordaje}

El envenenamiento ofídico es un problema de salud que afecta a cerca de 2,7 millones de personas en el mundo, principalmente, en regiones tropicales y subtropicales (Kasturiratne et al., 2008). Entre 300 y 400.000 de estos envenenamientos resultan en amputaciones y otras secuelas físicas que limitan la movilidad de las personas afectadas. Por lo que se estima que cada año, más de

personas pierden la vida como consecuencia de este padecimiento, especialmente en el suroeste asiático y en África Subsahariana (Gutiérrez et al., 2006; Kasturiratne et al., 2008). Estas estadísticas hacen del accidente ofídico un padecimiento con mayor mortalidad que el de muchas enfermedades contagiosas como: dengue, fiebre amarilla o el mal de Chagas (Williams et al., 2010). Menos conocido aún es el impacto a nivel psicológico, que muchas veces desencadena depresiones o fobias, o las consecuencias socioeconómicas que afectan, principalmente, a sectores, ya de por sí. económicamente deprimidos en algunas zonas rurales (Gutiérrez et al., 2015). A pesar de esta situación, el accidente ofídico, solo recientemente, fue incluido en la lista de enfermedades desatendidas de la Organización Mundial de la Salud (WHO [por sus siglas en inglés], 2019), lo que se espera contrarreste el enorme retraso que existe para dar soluciones definitivas en las regiones donde el impacto mayor (Williams et al., 2019).

Los países latinoamericanos no son ajenos a las repercusiones de este problema de salud, estimándose unos 57,500 envenenamientos anuales en esa región (Chippaux, 2017). La tremenda biodiversidad que caracteriza los países que integran Latinoamérica se ve reflejada en cerca de 180 especies de serpientes venenosas, donde se incluyen 97 víboras (Campbell y Lamar, 2004), así como el hecho que una importante proporción de su población se dedica a la agricultura en zonas rurales (Altieri, 2000) explica en gran medida el porqué de esa alta incidencia.

El antiveneno o suero antiofídico es el único tratamiento efectivo para el envenenamiento por mordedura de serpientes y consiste en una preparación de anticuerpos específicos para neutralizar las toxinas que componen el veneno de las serpientes (Gutiérrez, 2002). Varios centros productores de antivenenos operan en la región para satisfacer la demanda de antivenenos en Latinoamérica (Fan et al., 2019). Entre los centros productores de mayor renombre e impacto a nivel local y regional se sitúa el Instituto Clodomiro Picado (ICP), un centro de investigación y producción de sueros antiofídicos y otros inmunobiológicos que pertenece a la Universidad de Costa Rica (UCR). Desde 1970, el Instituto Clodomiro Picado ha mantenido su misión de "contribuir a la solución del problema de los envenenamientos por animales ponzoñosos en Costa Rica y otros países, así como al desarrollo científico-tecnológico nacional, mediante un esfuerzo de grupo que involucra actividades de investigación, docencia, acción social y producción" (Gutiérrez, 2019). En estas cinco décadas, el ICP ha llegado a reducir el impacto del envenenamiento por serpientes en nuestro país y otros países de la región, de tal manera que se constituye como una institución líder a nivel internacional en el estudio, prevención y elaboración de los productos terapéuticos contra envenenamientos por serpientes.

En celebración de su 50 aniversario y a la ininterrumpida labor en la generación de conocimiento y la producción de antivenenos y otros inmunobiológicos, este trabajo resume algunos de los más significativos aportes del colectivo científico asociado a este instituto. Por lo que esta se considera una historia exitosa y un importante ejemplo de cómo la universidad pública cumple un importantísimo papel en el desarrollo científico y tecnológico de un país y en el bienestar de su sociedad.

\section{El legado del Dr. Clodomiro Picado Twight}

Nos sumus sicut nanus positus super humerus gigantis (somos enanos sobre hombros de gigantes). En el desarrollo científico, donde el conocimiento se construye a partir de información que ha sido generada anteriormente, la frase del obispo y educador anglosajón Juan de Salisbury es tan vigente hoy como cuando fue acuñada en 1159. En contraste con otros países tropicales, la lucha antiofídica en Costa Rica contó desde sus inicios con gigantes visionarios que dejaron un importante legado tanto de conocimiento científico como de gestión en torno al tratamiento del envenenamiento ofídico en el país. Sin duda, el referente de estos esfuerzos fue el Dr. Clodomiro Picado Twight (Fig. 1), quien durante la primera mitad del siglo XX abordó el tema del envenenamiento ofídico desde el Laboratorio Clínico del Hospital San Juan de Dios (Zeledón, 1999). Clorito Picado, como cariñosamente era llamado, actuó como director de este laboratorio cuando regresó de sus estudios de doctorado en la Universidad de la Sorbona en Francia (Gutiérrez y Nájera, 1989). 
Dentro de los múltiples temas que abordó relacionados con salud, el estudio de las serpientes venenosas y sus efectos ocupó gran parte de su agenda. Para ello, creó un pequeño serpentario en el hospital y estableció una red de contactos para abastecerse de serpientes. Asimismo, logró resumir sus observaciones en su clásico libro "Serpientes Venenosas de Costa Rica. Sus Venenos. Seroterapia Antiofidica", publicado en 1931 (Fig. 1). Esa obra condensa aspectos tan variados como distribución y ecología de las serpientes venenosas conocidas en la época, efectos de sus venenos y subraya la importancia de emplear el suero antiofídico como único tratamiento efectivo contra el envenenamiento por estos animales (Picado, 1931).

El Dr. Picado envió venenos de nuestras serpientes para la producción de un antiveneno específico para Costa Rica al Instituto Butantán de Brasil. Además, promovió la Ley de Defensa contra el Ofidismo de 1926, que entre otras cosas señalaba la responsabilidad del estado para tratar el envenenamiento ofídico. Esta Ley marcó un hito en el posterior tratamiento del envenenamiento ofídico del país, al responsabilizar a los patronos, y subsecuentemente al Estado, del tratamiento de los pacientes envenenados, y mostró que el accidente ofídico es un problema de salud laboral.

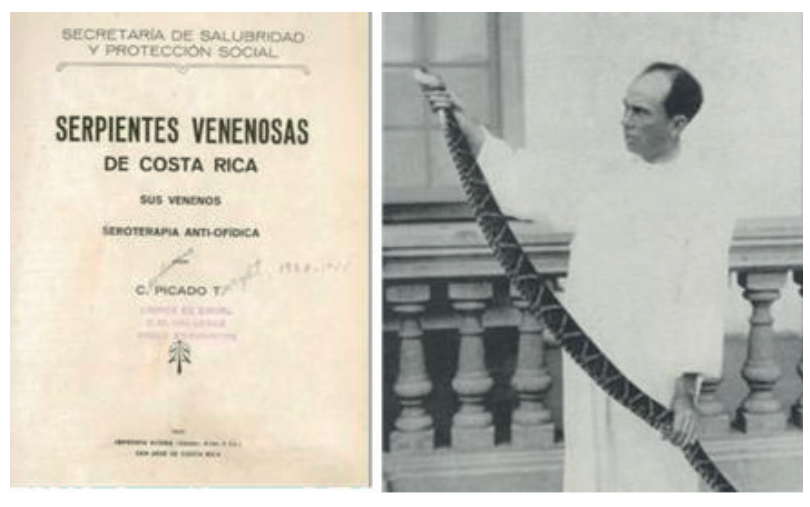

Figura 1. Dr. Clodomiro Picado Twight (1887-1944) y portada de su libro sobre serpientes venenosas, publicado en 1931. Fuente: Fotografía archivos Instituto Clodomiro Picado.

\section{Programa de Sueros Antiofídicos: los inicios del ICP}

Después de su prematura muerte en 1944, el legado del Dr. Clodomiro Picado continuó con sus colaboradores desde el Hospital San Juan de Dios (Gutiérrez, 2010). Para mediados de los años sesenta, el país estaba listo para iniciar una incursión más seria en la producción de su propio antiveneno. En 1967, se inicia el Programa de Sueros Antiofídicos, a partir de un esfuerzo conjunto entre el Ministerio de Salubridad Pública de la época, impulsado por su ministro el Dr. Álvaro Aguilar Peralta, el programa de cooperación de Estados Unidos de América, en la figura del coronel Hershell Flowers y la Universidad de Costa Rica (UCR) (Fig. 2). El coronel Flowers era veterinario de profesión y tenía experiencia en el manejo de serpientes venenosas. En esa época, laboraba en el cuerpo de ingenieros del Ejército de los Estados Unidos. De parte de la UCR, le correspondió participar al profesor Roger Bolaños (Ph.D. Universidad de Tulane, 1964), microbiólogo y en ese momento director del laboratorio de inmunología de la Facultad de Microbiología (Fig. 2). Ese mismo año se crea, mediante decreto presidencial, la Comisión Nacional contra el Ofidismo, la cual tenía entre sus diversas funciones, la investigación y estudio de las serpientes y los envenenamientos, y el asesoramiento técnico a organismos oficiales sobre el tema.

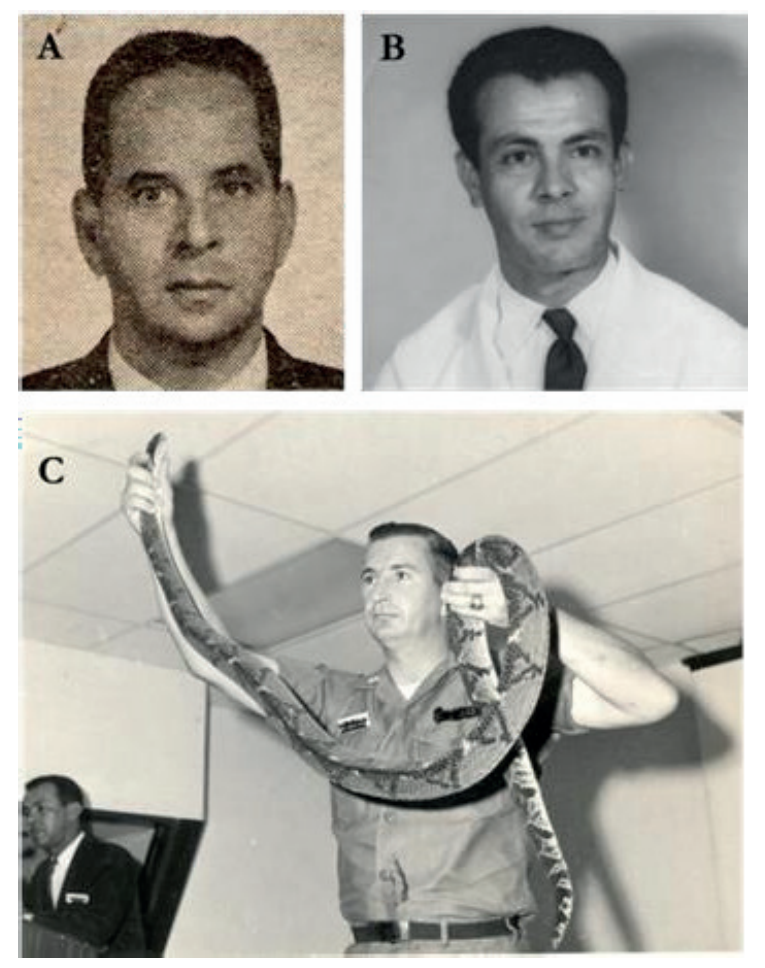

El primer lote de suero antiofídico fue producido en Figura 2. Figuras clave en la formación del Programa de Sueros Antiofidicos en 1967. (A) Dr. Alvaro Aguilar ministro de Salubridad Pública (foto archivos Ministerio de Salud) (B) Dr. Roger Bolaños, Facultad de Microbiología, Universidad de Costa Rica. (C) Coronel Hershell Flowers, Cuerpo de Ingenieros, USA. (A y B, Fotografías archivos ICP). Fuente: Instituto Clodomiro Picado. 
1967, lo que provocó gran expectativa en el entorno médico del país. Durante esa época otro acontecimiento clave fue la participación como consultor internacional del Dr. Aristides Vallejo-Freire, exdirector del Instituto Butantan, quien en su informe subrayó la necesidad de que el país contara con su propia producción de antivenenos (Gutiérrez, 2010). El Dr. Vallejo-Freire indicó que la forma como se estaba produciendo el suero debía evolucionar hacia una mejor organización y que debía escalar para poder lograr sostenibilidad, y centralizar las operaciones en un solo lugar. Además, subrayó la importancia, así como la necesidad, de que la orientación científico-técnica fuera dada por la UCR, y que sería conveniente que el proyecto contara con cierta autonomía (Gutiérrez, 2010). Algunas de estas observaciones fueron acogidas y así, poco tiempo después, la dirección del programa pasó a manos del Dr. Roger Bolaños y se decidió que el gobierno pidiera un préstamo a la Agencia Internacional de Desarrollo (AID) para la construcción del laboratorio y serpentario en una finca que el Ministerio de Salubridad puso a disposición en Dulce Nombre de Coronado, en el noroeste de San José, que para ese momento era un lugar rural. En honor al distinguido científico, se propuso que estas instalaciones llevaran el nombre de Laboratorio Seroterápico Dr. Clodomiro Picado. Las obras concluyeron el 13 de abril de 1970, fecha que se considera la fundación del Instituto Clodomiro Picado.

Se puede imaginar la alegría y entusiasmo con que se abordó la faena durante esos primeros años, cuando el instituto contaba con apenas diez trabajadores, dentro de ellos se incluía al Dr. Roger Bolaños como su primer director (Fig. 3). Las labores eran realizadas en conjunto y los trabajadores tenían un claro entendimiento de todos los aspectos relacionados con la producción de antivenenos. Las instalaciones consistían en dos pequeños edificios conectados por un pasadizo: en uno se alojaba la oficina de la dirección, el serpentario y un breve espacio para charlas, mientras que la otra albergaba un par de laboratorios generales donde se procesaba el plasma y se hacía investigación (Fig. 4). Para 1972 se firma un convenio entre el Ministerio de Salubridad Pública y la Universidad de Costa Rica para que el proyecto continuara bajo la jurisdicción de la UCR. Sin duda la labor y liderazgo del Dr. Bolaños permearon para que esta decisión, que el tiempo demostró ser muy conveniente, se concretara (Gutiérrez, 2010).

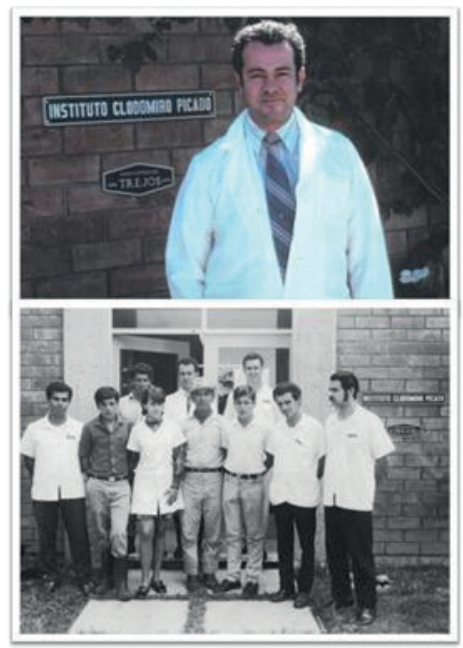

Figura 3. Dr. Roger Bolaños en el recientemente creado Instituto Clodomiro Picado (foto superior, cortesía Federico Bolaños) y primeros trabajadores del instituto (fotografía inferior). Arriba de izquierda a derecha: Juvenal Sánchez, Roger Bolaños, Richard Taylor, Guillermo Flores, un funcionario no identificado, Hilda Herrera, Carlos Ramírez, Gerardo Serrano, Álvaro Flores, Osvaldo Marín (Fotografía archivos ICP). Fuente: Instituto Clodomiro Picado.

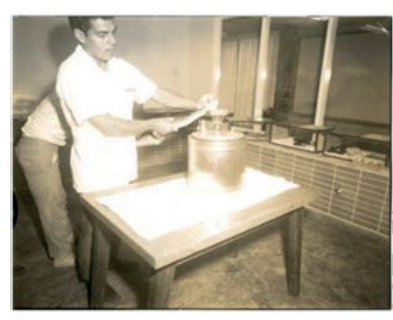

Serpentario: extracción de veneno

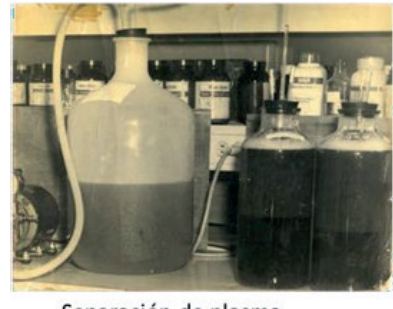

Separación de plasma

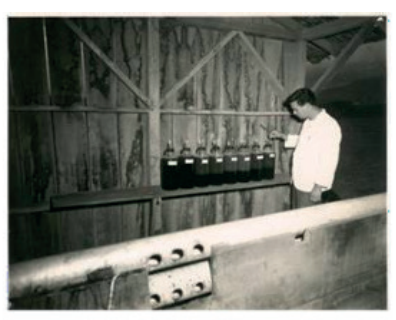

Recolección de sangre de caballo

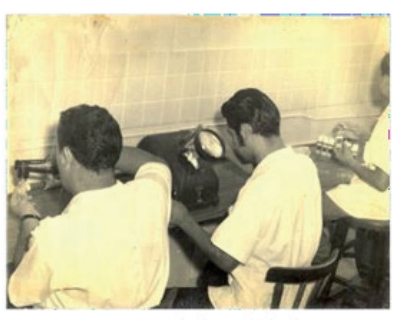

Control de Calidad
Figura 4. Inicio de la producción de antivenenos en el Instituto Clodomiro Picado. Fuente: Instituto Clodomiro Picado.

\section{Visión y Liderazgo: los años setenta en el ICP}

La visión y el liderazgo constituyen ingredientes imprescindibles para consolidar un grupo exitoso de investigación científica. La visión muestra el estado o situación al que el colectivo aspira llegar en el futuro. El liderazgo 
consiste en el conjunto de habilidades gerenciales o directivas de un individuo que influyen en la forma de ser o actuar de las personas que integran el grupo de trabajo, lo que permite trazar la ruta hacia la realización de la visión.

Sin duda, el liderazgo del Dr. Roger Bolaños fue clave para consolidar al naciente instituto y asentarlo sobre sólidas bases académicas. El Dr. Bolaños enmarcó la producción de antivenenos dentro del ámbito universitario, para proteger al instituto de los vaivenes políticos. Siendo un aplicado académico, el Dr. Bolaños logró leer la necesidad de que la producción de sueros antiofídicos se acompañara de los ejes fundamentales de la Universidad de Costa Rica: un sólido programa de investigación, la divulgación de conocimiento hacia distintos sectores de la población y por supuesto, la educación universitaria, tanto a nivel de grado como de posgrado, para contribuir en la formación de profesionales y académicos del país y de la región (Fig. 5). Como se verá en las siguientes líneas, estos cuatro ejes se fortalecen simultáneamente y han sido esenciales en el quehacer del instituto a lo largo de estos 50 años.

\section{ICP como proyecto regional}
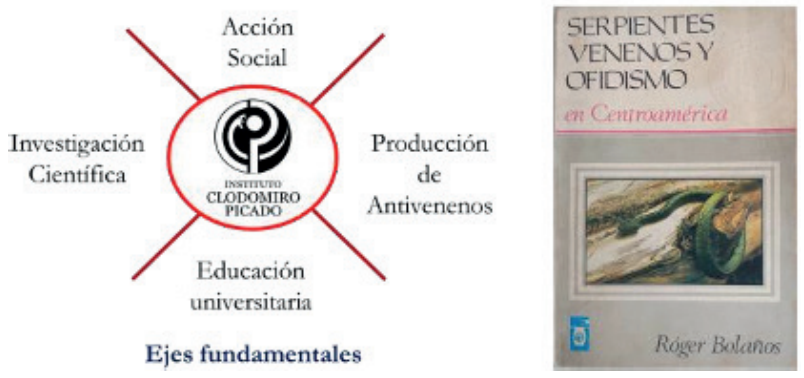

Figura 5. Más allá que la fabricación de sueros para Costa Rica, el Dr. Bolaños visualizó al ICP como un proyecto regional, asentado en las bases del quehacer de la Universidad de Costa Rica: investigación, educación universitaria y la extensión. A la derecha, portada de su libro Serpientes, Venenos y Ofidismo en Centroamérica, publicado por la Editorial UCR en 1984. Aunque esta obra se publicó después de su salida del ICP, recopila muchas de sus experiencias como investigador y director del instituto. Como muchas de sus obras, refleja su visión de que la producción científica y tecnológica tuviera impacto fuera de nuestras fronteras. Fuente: Instituto Clodomiro Picado.

El Dr. Bolaños además fue un visionario que muy temprano identificó la necesidad de desarrollar el plan de producción desde una perspectiva más allá de las necesidades nacionales, para trasladarlo a un contexto regional.
No es en vano que una de sus obras más representativas, Serpientes Venenosas de Centroamérica, publicada unos años después, lleva la huella de esa visión regional (Fig. 5). Ese enfoque internacional del Dr. Bolaños se refleja también en la docencia. Desde temprano, el instituto ha sido clave en la formación de académicos de otros países de la región y la lista de pasantes internacionales que han realizado investigaciones en el ICP es enorme. Bolaños inició un programa de investigación no solo centrado en temas de producción, sino en la integración de nuevos conocimientos sobre la composición de venenos, así como de las serpientes que los producen. De hecho, los primeros esfuerzos se enfocaron precisamente en detallar la distribución de las especies de serpientes venenosas del país, así como en catalogar aspectos de su biología como descripción de cariotipos.

A pesar de su importancia, y de establecer a la investigación científica como el motor del ICP, la investigación inicial todavía se centraba en los pocos investigadores del instituto de ese entonces y se recurría, principalmente, a revistas de carácter nacional. Todo esto estaba a punto de cambiar precisamente con la llegada de nuevo recurso humano al instituto hacia finales de la década de $\operatorname{los} 70 \mathrm{y}$ principios de los 80 , la mayoría de ellos destacados profesores de nuestras universidades públicas.

\section{Perfilando las líneas de investigación: la dé- cada de los ochenta}

La llegada de jóvenes investigadores con experiencia internacional, entre ellos los doctores Luis Cerdas (M. Sc. en Microbiología, Universidad de Costa Rica, 1979), Edgardo Moreno (Ph. D., University of Wisconsin-Madison, 1979), José María Gutiérrez (Ph. D., Oklahoma State University, 1984) y posteriormente Bruno Lomonte (Ph. D., Goteborg University, Suecia, 1994), lo que sin duda catapultó el incipiente programa de investigación del instituto y lo ayudó a consolidarse. A ellos se unieron, posteriormente, los microbiólogos Olga Arroyo, Fernando Chaves, José Antonio Gene, Gustavo Rojas y Ermila Rojas.

Con estos nuevos actores, las líneas de investigación del instituto empiezan a perfilarse. El aislamiento de toxinas específicas del veneno, así como sus efectos fisiopatológicos acaparan la atención de estos investigadores (Gutiérrez y Chaves, 1980; Arroyo y Cerdas, 1984; Lomonte y Gutiérrez, 1983). 
Además, se continúan las descripciones de cariotipos de serpientes del país, con un fuerte trasfondo en su evolución (Gutiérrez et al., 1979; Espinoza et al., 1980; Gutiérrez y Bolaños, 1981). También, surgen una serie de interesantes artículos sobre la capacidad neutralizante del suero de la serpiente zopilota Clelia clelia, que se alimenta de víboras venenosas (Cerdas y Lomonte, 1982; Lomonte et al., 1982, 1989).

En la década de los ochenta inicia, además, una serie de estudios con un perfil un tanto diferente, más relacionado con la investigación tecnológica. Estos proyectos estaban claramente orientados al mejoramiento del proceso de producción de antivenenos, puesto que se enfocaban en resolver situaciones que dificultaban el proceso productivo (Gené et al., 1986; Gutiérrez et al., 1988a, 1988b). La publicación de estos trabajos empezó la temática en los procesos de producción y mejoramiento de antivenenos, que con el tiempo evolucionaría hacia uno de los campos más fructíferos del ICP.

También, en esa época se establecen estudios sobre aspectos de historia natural de serpientes, especialmente, aquellos relacionados con su dieta y biología reproductiva. Los aportes tempranos de Soledad Martínez (Martínez y Cerdas, 1986), pero, principalmente, los esfuerzos de Alejandro Solórzano (Solórzano y Cerdas, 1984, 1986; Solórzano et al., 1987) permitieron asegurar esta línea de investigación. Es importante recordar que las serpientes son animales solitarios y de hábitos discretos, por lo que su estudio en condiciones naturales es sumamente difícil y laborioso. Estos investigadores, y quienes los precedieron, lograron tomar ventaja del arribo de cientos de serpientes al Serpentario para lograr develar mucha de la información que, sobre ecología de nuestros ofidios, reconocemos actualmente.

Es claro entonces que, a partir de este periodo, la investigación científica adquiere una mayor relevancia en el quehacer del instituto, primero bajo la dirección del Dr. Luis Cerdas Fallas, pero especialmente, bajo el liderazgo del Dr. José María Gutiérrez, desde su gestión como director a finales de la década de los ochenta. Evidencia de este hecho es el incremento en la publicación de artículos científicos en este periodo, patrón que ha continuado progresando desde entonces (Fig. 6).

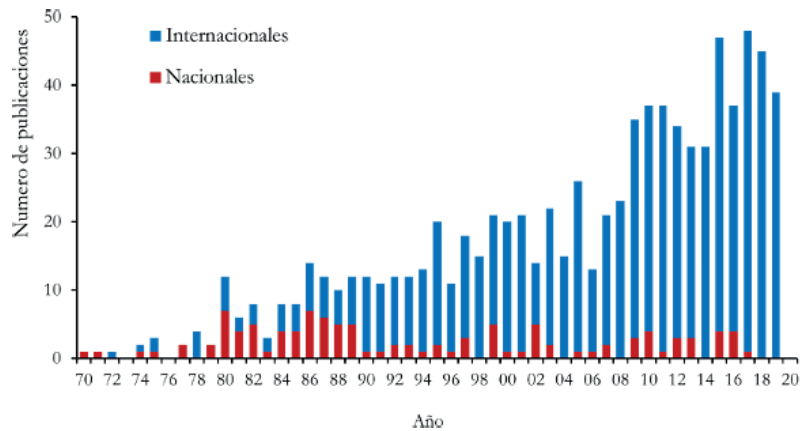

Figura 6. Número de publicaciones científicas realizadas en el ICP. Periodo 1970-2019. Fuente: Instituto Clodomiro Picado.

Un fenómeno muy interesante es que el aumento en la producción científica en ese periodo va acompañado de una mayor diversidad de revistas arbitradas donde se presentan los resultados de las investigaciones, además de que hay un notable cambio en la proporción de artículos publicados en revistas nacionales que poseen un carácter más local, para dar paso a una mayor presencia en revistas internacionales (Lomonte, 2012). Este punto es medular para posicionar el quehacer científico del ICP en la escala global, y es una manera también de exponer los estudios realizados en esta institución pública al escrutinio científico de una mucho mayor, y más demandante, audiencia.

\section{Consolidación de nuevos investigadores e in- fraestructura: la década de los noventa}

El cambio de década encontró al ICP con un sólido programa de investigación, pero con algunas limitaciones en cuanto a sus posibilidades de crecimiento y diversificación. Una de las restricciones medulares tenía que ver con la escasa experiencia internacional de varios de los cuadros profesionales de planta y que los investigadores con título académico a nivel de doctorado continuaban siendo minoría. Al mismo tiempo, un grupo de jóvenes investigadores y estudiantes graduados apoyaba la investigación científica del instituto desde posiciones temporales como asistentes o instructores, pero estaban deseosos de continuar sus estudios de posgrado. Esta situación restringía las posibilidades de búsqueda de fondos en foros internacionales, limitaba la cooperación con grupos de investigación en el extranjero y centralizaba mucha de la actividad científica en aquellos investigadores que contaban con mayor experiencia internacional. El paso lógico era preparar nuevos cuadros de investigadores para revertir esa situación. 
Algunos acontecimientos promovieron el crecimiento profesional y académico de investigadores del ICP, lo cual catapultó la dirección que seguiría su programa de investigación en el futuro. En primer lugar, la salida casi sincrónica de varios jóvenes investigadores a realizar sus doctorados en prestigiosos centros el extranjero, entre ellos: Alberto Alape (Ph. D., Karolinska Institute, Suecia, 1997); Cecilia Díaz-Oreiro (Ph. D., MD Anderson Cancer Center-University of Texas at Houston, 1998), Mahmood Sasa (Ph. D., University Texas at Arlington, 2000), Marietta Flores (Ph. D. Karolinska Institute, Suecia, 2001).

Otro evento importante fue el establecimiento del Programa de Doctorado en Ciencias de la Universidad de Costa Rica, que formalmente comenzó en 2001, pero que fue gestándose como idea concreta hacia finales de los 90. Este programa permitió a aquellos investigadores con maestría, que por razones personales no tenían la oportunidad de salir del país, siguieran su crecimiento académico. El programa nacional de doctorado posee una concreta agenda de investigación y requiere que sus participantes cumplan con pasantías en instituciones reconocidas en el extranjero. Aunque los primeros egresados de este programa surgirían unos años después, las bases del programa fueron asentadas hacia mediados de esa década. Precisamente, los primeros egresados fueron investigadores que ya laboraban en los años 90 en el ICP: Yamileth Angulo (Doctorado en Ciencias, 2005), Alexandra Rucavado (Doctorado en Ciencias, 2006), Fernando Chaves (Doctorado en Ciencias, 2006), Guillermo León (Doctorado en Ciencias, 2008).

Paralelo a los esfuerzos por consolidar el personal académico, otro rasgo de este periodo es el impulso en la infraestructura del instituto, en donde se involucró, entre otras obras, la construcción de una planta de producción. Como se mencionó anteriormente, la actividad de producción había estado limitada a un espacio reducido en el edificio original, por lo que establecer un edificio destinado exclusivamente a la producción representó una mejora significativa no solo para acomodar mejor los equipos, sino, además, para asegurar la higiene y esterilidad en gran parte del proceso. La energía del Dr. José María Gutiérrez, director durante la primera mitad del decenio, así como del Dr. Gustavo Rojas como director desde mediados de la década de los noventa fue clave para dichos desarrollos.

Así, la producción del suero antiofídico se constituye desde entonces como empresa biotecnológica, donde el dinero que ingresa por la venta de sueros puede utilizarse en la compra de equipo y recursos para investigación y desarrollo. Gracias a fondos obtenidos por la venta de sueros, así como a una partida presupuestaria de la Universidad, se logra la construcción del nuevo edificio para instalar los procesos de procesamiento de plasma, control de calidad y envasado del antiveneno (Fig. 7).

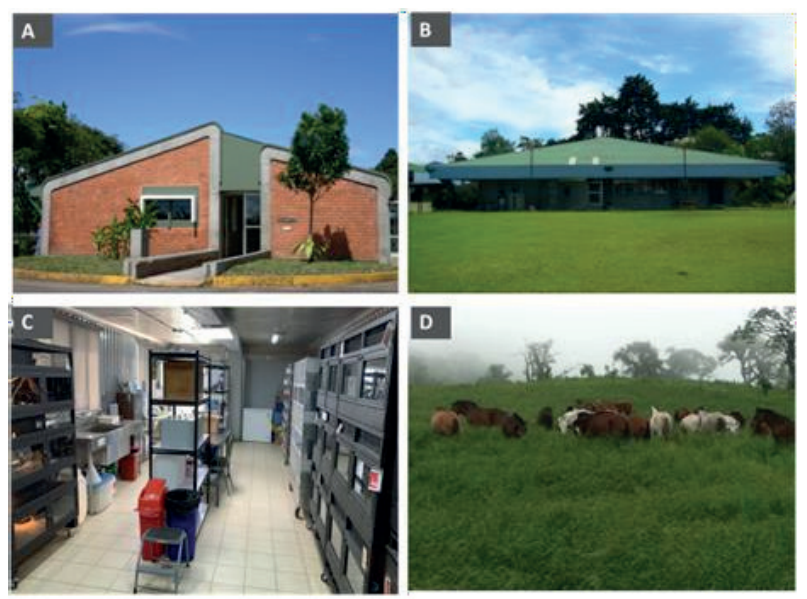

Figura 7. Infraestructuras mayores del ICP. (A) Edificio de laboratorios de investigación. (B) Planta de procesamiento de sueros. (C) Bioterio y serpentarios. (D) Finca el Corralito, Cascajal de Coronado. Fuente: Instituto Clodomiro Picado.

Las contribuciones al proceso de producción no se limitaron a la infraestructura, sino que además se realizaron aportes significativos en aspectos básicos y tecnológicos de la fabricación de antivenenos, por ejemplo, se estudia la respuesta inmune y los efectos que, el inmunizar con veneno, produce en los caballos empleados en la producción de anticuerpos, cuyos trabajos fueron promovidos por el Dr. Ricardo Estrada, veterinario del Instituto, en colaboración con otros investigadores (Estrada et al., 1991, 1992). Un desarrollo crucial durante este periodo fue el implementar nuevas metodologías para la producción de antivenenos a partir de la purificación de anticuerpos con ácido caprílico (Rojas et al., 1994). Básicamente, la purificación de inmunoglobulinas se logra a partir de la precipitación de proteínas plasmáticas que no son anticuerpos bajo condiciones fisicoquímicas particulares, lo que resulta en un filtrado más rico, más puro y que induce a menos reacciones adversas. El implementar este proceso redujo, considerablemente, los costos de producción y el tiempo requerido en la etapa de fraccionamiento, lo que, además, mostró mejores rendimientos que el método anterior con sulfato de amonio. Por estas razones, este 
desarrollo ha sido la base del proceso de purificación en el ICP en los últimos 25 años. Además, se incorporó la informática como herramienta de apoyo a las actividades productivas y de control de calidad (Robles y Gutiérrez, 1989).

Mientras tanto, las investigaciones en los distintos ejes temáticos continuaron durante este periodo. Digno de mencionar son los esfuerzos por aislar y caracterizar miotoxinas de venenos de serpientes de Costa Rica y otros países de la región, así como los estudios realizados para explicar el mecanismo de acción de este tipo de toxinas (Díaz et al., 1992, 1994; Lomonte et al., 1994; Gutiérrez y Lomonte, 1997). Estos progresos continuaron a su vez en otro tipo de componentes del veneno, como son las metaloproteinasas, promovidos por la Dra. Alexandra Rucavado y sus colaboradores (Rucavado et al., 1995a, b). Las metaloproteasas son toxinas que degradan proteínas de la matriz extracelular de los vasos sanguíneos, por lo que en gran medida son responsables del efecto hemorrágico característico del envenenamiento por muchas especies de víboras.

Como resultado de estos aportes, en la década de los 90, también se incrementó la producción anual de publicaciones científicas, llegando prácticamente a duplicarse hacia la segunda mitad del decenio (Fig. 6).

\section{Desafíos de un nuevo milenio: el ICP en el si- glo XXI}

Si los noventa fue una época marcada por la preparación de personal y el desarrollo de infraestructura, es en el nuevo milenio donde el ICP se consolida como un centro académicamente maduro y líder en el abordaje del accidente ofídico a nivel regional.

Por un lado, el volumen y diversidad temática de los proyectos de investigación continúa en franco crecimiento, al punto que en estos últimos años el número de publicaciones anuales vuelve a duplicar la producción de principios de este siglo (Fig. 6). Este crecimiento resulta de múltiples factores. Por otro lado, el incremento del número de investigadores activos, que como se indicó en párrafos anteriores, vino a reforzar el recurso académico del instituto. Además, se fortaleció la Sección de Desarrollo Tecnológico, el cual se constituyó como un equipo de investigación dirigido al desarrollo y mejoramiento de los productos inmunobiológicos fabricados en el ICP, lo que consolida la línea de investigación en mejoramiento iniciada años atrás. Como se verá más adelante, el incremento de investigadores promueve a su vez una mayor colaboración con otros grupos, especialmente internacionales, lo que resulta en nuevas alianzas comprometidas con la investigación.

El crecimiento en infraestructura continuó, también, en los primeros años del nuevo siglo. Entre otros proyectos, se destaca la construcción de un edificio para albergar un nuevo serpentario, lo que triplicó el espacio asignado al mantenimiento de las serpientes productoras del veneno empleado en la inmunización de los caballos y en la investigación toxicológica (Fig. 7). Esta construcción vino a solucionar aspectos cruciales en la sobrevida de las serpientes en cautiverio: la disponibilidad de un cuarto de ingreso, que pudiera actuar a modo de cuarentena, cubículos donde se puedan mantener especies con requerimientos climáticos diferentes, y la posibilidad de realizar disecciones y otros trabajos en un área distinta al recinto de mantenimiento. Los cubículos para cada especie contaban ahora con sus propios equipos de manejo (ganchos, pinzas, tubos acrílicos y otros) por lo que la higiene podía ser controlada apropiadamente. Las mejoras en las condiciones de las serpientes motivaron además la evaluación y reformulación de los procedimientos de manejo y registro de los animales que ingresan, lo que derivó en los protocolos empleados actualmente.

Este periodo marcó, además, la expansión del instituto, al adquirir la Finca El Corralito en Cascajal de Coronado (Fig. 7). Este movimiento permitió trasladar el manejo de los caballos productores a una nueva localidad, lo que logró resolver dos importantes retos. Por un lado, el predio original donde se instalaba el ICP ya no era lo suficientemente extenso para mantener un número cada vez mayor de caballos. Por otro lado, Dulce Nombre de Coronado había dejado de ser el lugar agreste de los años 70 , y ahora era un suburbio más de la ciudad. La presión por eliminar el manejo de caballos en un área residencial y comercial era ahora enorme.

El resolver el problema de espacio para los caballos fue el primer paso en una serie de importantes decisiones tendientes a diversificar la producción de antivenenos y cubrir así la demanda de nuevos mercados. El ICP pasó de ser un productor para la región centroamericana, a incursionar mercados en países del noroeste de Sudamérica, África Subsahariana e incluso Papúa-Nueva Guinea (Gutiérrez, 2019). Estos logros se basan en gran medida en investigación básica y preclínica generada a partir de 
la sección de desarrollo tecnológico mencionada anteriormente y a los esfuerzos de los doctores Yamileth Angulo y Alberto Alape, directores del Instituto durante ese periodo.

\section{Líneas de Investigación del ICP}

El análisis de las 827 referencias publicadas desde 1970 hasta el año 2019 evidencia las temáticas abordadas por el colectivo de investigadores en estas cinco décadas. Además, la proporción de referencias en cada tema permite una cruda, pero pertinente, forma de sopesar la importancia relativa que tienen esos tópicos en el quehacer del ICP (Fig. 8). Así, la caracterización bioquímica de toxinas y los venenos (30\%), la patología y mecanismos de acción de esas toxinas (18\%), la capacidad neutralizante de los antivenenos e inhibidores ante venenos específicos (22\%), y la biología y evolución de serpientes y otros animales venenosos (12\%), son los contenidos más prolíficos. Este resultado no es sorprendente si consideramos que esos cuatro tópicos están directamente vinculados a la misión de resolver el problema del envenenamiento. Sin embargo, otros temas completan el abordaje holístico que desde el ICP se hace del accidente ofídico, como son la vigilancia epidemiológica (Arroyo et al., 1999; Sasa y Segura-Cano, 2020) y el análisis de políticas de salud en torno al accidente ofídico (Gutiérrez y Pereañez, 2016). Además, aspectos como el estudio de toxinas de bacterias y sus mecanismos de infección (Flores-Díaz et al., 2016; Zúñiga-Chaves et al, 2016) y, más recientemente, los estudios sobre arácnidos y otros invertebrados venenosos (Díaz et al. 2019; Rojas-Azofeifa et al., 2019) muestran la variedad de intereses del colectivo científico del instituto.

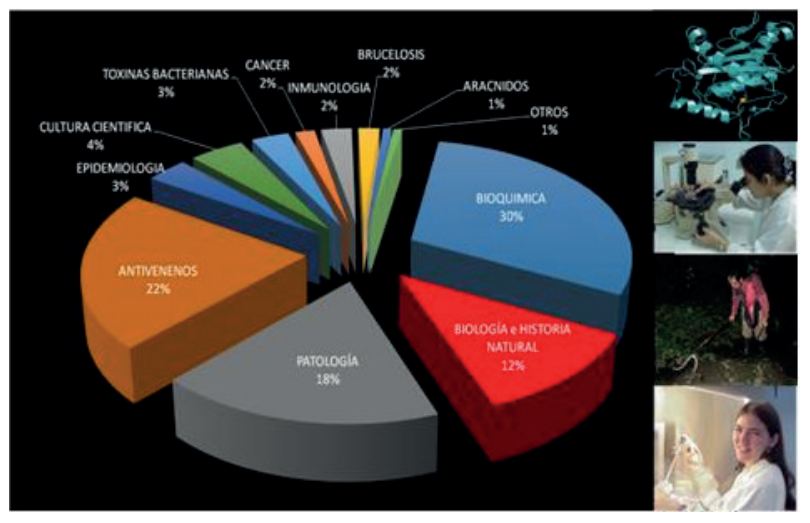

Figura 8. Diversidad de temas de investigación en el ICP en relación con el número de publicaciones en ellos. Periodo 19702019. Fuente: Instituto Clodomiro Picado.
Las distintas temáticas de investigación no han tenido la misma evolución en el tiempo, como se muestra en la Fig. 9 para las cuatro líneas mayores. Mientras que aspectos de biología de animales venenosos y los de fisiopatología han tenido un crecimiento casi constante en el tiempo, la caracterización bioquímica de venenos y los estudios sobre antivenenos han tenido un importante repunte en la última década. El surgimiento y aumento de trabajos en estas líneas de investigación es consecuencia de acciones concretas de uno o pocos investigadores, pero su mantenimiento en el tiempo se relaciona con otro rasgo característico del quehacer científico del ICP: las colaboraciones con otros grupos de investigación.

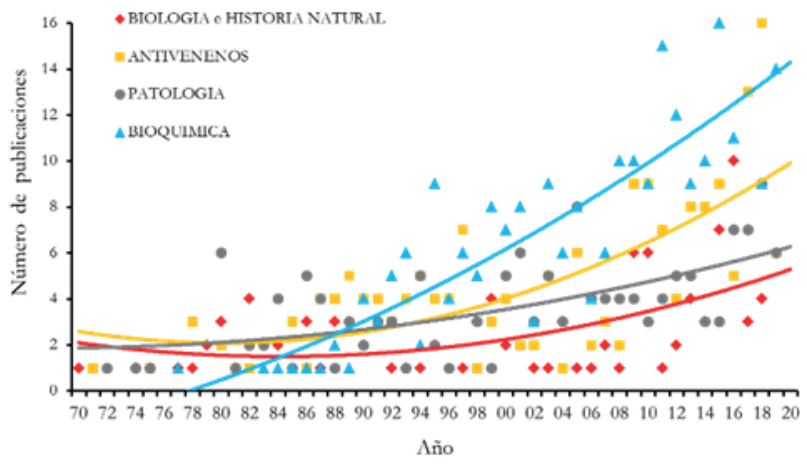

Figura 9. Trayectoria en el tiempo de temas principales de investigación en el ICP. Periodo 1970-2019. Fuente: Instituto Clodomiro Picado.

\section{Colaboración como eje fundamental del co- lectivo científico}

La colaboración es una práctica común entre grupos de investigación y es considerada una de las estrategias más eficientes para avanzar agendas de mutuo interés. A través de la colaboración, investigadores o grupos de investigación logran solventar sus propias limitaciones, para establecer un vínculo donde cada parte gana de la participación de la otra (Katz y Martin, 1997).

Aunque existen mecanismos formales para establecer acuerdos de cooperación entre grupos y garantizar beneficios mutuos de ellos, la mayoría de las interacciones de colaboración surgen espontáneamente, de manera usual en las conversaciones entre presentaciones de congresos. En gran medida, esta ha sido la tónica en muchas de las colaboraciones más perdurables y significativas en el ICP (Gutiérrez, 2019a).

Un análisis bibliométrico muestra el crecimiento en el número de coautores extranjeros en las publicaciones 
del ICP y evidencia esa tendencia a incrementar las interacciones con otros grupos de investigación (Lomonte, 2012). Hay cinco factores que hacen atractiva la idea de colaborar con el ICP por parte de grupos de investigación:

(1) Acceso a elementos de biodiversidad. Especialmente, para grupos extranjeros, la diversidad biológica de Costa Rica y en particular la oportunidad de acceso a elementos de su diversidad ofídica, hacen del ICP un centro atractivo.

(2) Profundo conocimiento de toxinología y fisiopatología de venenos de serpientes. La experiencia en este campo por parte de los investigadores del ICP provee una sólida base teórica y práctica a nuevos estudios toxinológicos y asegura de esta manera su éxito.

(3) Disponibilidad de ensayos in vitro e in vivo para determinar efectos de toxinas y capacidad neutralizante de antivenenos. A pesar de las regulaciones, es todavía posible realizar ensayos con animales experimentales en Costa Rica, y el ICP posee bioterios que los producen. En el campo de la toxinología estos ensayos siguen siendo pruebas muy importantes para los estudios.

(4) Capacidad de producción de antivenenos en diferentes animales experimentales o de producción. El ICP dispone de toda una división de producción de anticuerpos a partir de animales experimentales. Además, se tiene conocimiento de cómo hacer escalamientos de producción, desde un nivel experimental a uno industrial o semiindustrial.

(5) Equipos y laboratorios. Si bien el ICP enfrenta restricciones económicas típicas de otros centros dentro de las universidades públicas del país y de Latinoamérica en general, a lo largo de su historia ha logrado acuñar una serie de infraestructuras y equipos básicos para la investigación. Las inversiones, además, cuentan con recursos que provienen de la venta de antivenenos y servicios, lo que ayuda al mantenimiento de la infraestructura científica. Actualmente, el ICP cuenta con un laboratorio de proteómica, pequeños laboratorios de histología y cultivo celular, entre otros, que lo hacen atractivo para otros grupos de investigación, tanto a nivel nacional como internacional.

Por su parte el ICP se beneficia de las colaboraciones a partir de los siguientes insumos:

(1) Acceso a conocimiento tecnológico o científicos en áreas nuevas de las que no se dispone de experiencia en el instituto.

(2) Intercambio de investigadores del ICP, que resulta en formación de recurso humano de alto nivel.
(3) Equipos, reactivos o materiales no disponibles en el ICP.

(4) Acceso a fondos en agencias internacionales o a concursos multiinstitucionales.

(5) Manejo informático, software y capacidades no disponibles en el ICP.

La experiencia en colaboraciones ha demostrado que grupos de investigación pueden potenciarse y fortalecerse a partir de estas alianzas estratégicas, para ampliar su margen de acción a partir de ellas (Gutiérrez y Rojas-Céspedes, 1999). Para ilustrar la importancia que la colaboración con otros grupos de investigación ha tenido en desarrollo científico del instituto, a continuación, se citan algunos ejemplos.

\section{Caracterización bioquímica de venenos}

Una de las colaboraciones más relevantes en los últimos años ha sido la cooperación con los doctores Juan José Calvete y Libia Sanz y su equipo del Instituto de Biomedicina de Valencia. Junto con estos investigadores iniciamos estudios de proteómica de venenos (el análisis de las proteínas contenidas en mezclas complejas), lo que llevó a consolidar el laboratorio de proteómica en el instituto, actualmente con la dirección del Dr. Bruno Lomonte (Fig. 10). La proteómica se enmarca entre las tecnologías "ómicas" que se han desarrollado en las últimas dos décadas gracias al advenimiento de mejores equipos de detección química y más poderosos algoritmos de análisis bioinformático (Lomonte y Calvete, 2017).

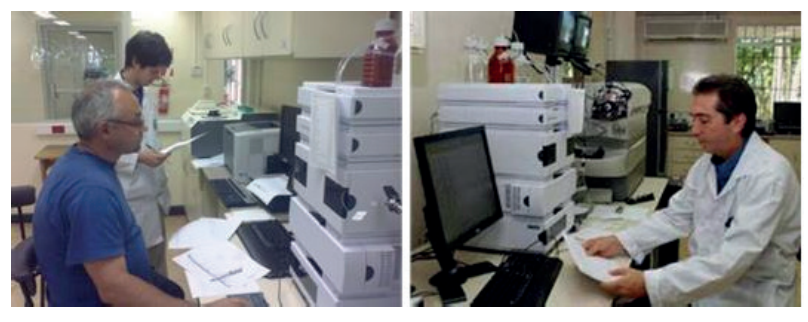

Figura 10. El Laboratorio de Proteómica en el ICP. Izquierda: Dr. Juan José Calvete colaborador del Instituto de Biomedicina de Valencia, España. Derecha: Dr. Bruno Lomonte, coordinador del laboratorio. Fuente: Instituto Clodomiro Picado.

El veneno de serpientes es una mezcla muy compleja de toxinas, mayormente proteínas, que puede incluir desde unas pocas toxinas hasta más de cien. El poder caracterizar bioquímicamente un veneno significa identificar esos componentes y su contribución en la mezcla final. Antes de la colaboración con el Dr. Calvete, el análisis 
completo de algunos venenos era una tarea laboriosa y lenta en el ICP, pues se requería aislar cada componente y secuenciarlo para determinar su identidad. Para esto se necesitaba gran cantidad de veneno, lo que dificultaba el completar el estudio en caso de serpientes pequeñas, que produjeran poco veneno, o que fueran poco comunes. $\mathrm{El}$ análisis proteómico en cambio requiere tan solo de unos miligramos de veneno y siguiendo un mismo procedimiento pueden identificarse los componentes del veneno rápidamente.

A partir de estos análisis se ha podido caracterizar el veneno de todas las serpientes de importancia médica en el país, lo que evidencia la tremenda diversidad de venenos entre nuestras especies (Lomonte et al., 2014; Fernández et al., 2015). No obstante, además de esa variación interespecífica, hemos registrado diferencias de la composición de veneno a nivel geográfico y ontogenético.

Los estudios de proteómica del veneno han revelado la huella filogenética de algunos componentes y han sido útiles para explicar por qué algunos venenos son neutralizados de mejor manera que otros por nuestros antivenenos. Por ejemplo, los venenos de serpientes coral son neurotóxicos, esto debido a la presencia de fosfolipasas A2 neurotóxicas o por otro tipo de proteínas conocidas como las toxinas de tres dedos (3FTx) que también actúan bloqueando el impulso eléctrico en las terminaciones neuronales (Fernández et al., 2015). Gracias a las caracterizaciones realizadas en el laboratorio de proteómica se ha identificado que hay dos patrones generales de venenos de corales, unos más ricos en toxinas de tres dedos y otros con mayor proporción de fosfolipasas neurotóxicas (Lomonte et al., 2016). Estos últimos en las especies de corales que forman un clado de especies filogenéticamente relacionadas y que evolucionaron en Norte y Centroamérica; mientras que los clados de origen sudamericano tienden a tener venenos ricos en 3FTxs. Nuestro antiveneno, elaborado a partir de un veneno rico en fosfolipasas A2 neurotóxicas, entonces, no es tan efectivo para neutralizar el veneno de especies del otro tipo, por lo que no es efectivo como tratamiento por mordeduras de coral en Sudamérica (Lomonte et al., 2016). Con esta nueva evidencia, estamos tratando de aumentar el espectro neutralizante de nuestro suero anticoral.

\section{Investigaciones para mejoramiento de anti- venenos}

Como se mencionó anteriormente, el proceso de producción constituye, también, una importante fuente de investigación, por lo que la mejora de antivenenos ha ido de la mano con el desarrollo científico y tecnológico del instituto. A través de los años se han adaptado y desarrollado una serie de métodos de laboratorio para evaluar las actividades tóxicas de los venenos y su neutralización por parte de antivenenos (Gutiérrez y Rojas-Céspedes, 1999). Recientemente, en la Sección de Desarrollo Tecnológico se logró implementar un nuevo procedimiento de purificación (Vargas et al., 2015), primero, diseñado para el fraccionamiento de plasma humano, pero que también puede incorporarse al proceso de producción de antivenenos equinos para lograr un producto aún más puro.

Estos aportes tecnológicos no han pasado desapercibidos por la comunidad internacional, y desde hace varios años se ha incrementado la relación que el ICP tiene con otros países que, como Costa Rica, sufren del flagelo de los envenenamientos por serpientes. Un ejemplo concreto es la producción de antivenenos para la región subsahariana de África, que inició como una colaboración con Nigeria para contrarrestar envenenamiento por varias especies de serpientes africanas. Este fue un esfuerzo triangulado entre el Ministerio de Salud de ese país, la Escuela de Medicina Tropical de Liverpool y la Universidad de Costa Rica (Gutiérrez et al., 2005, Segura et al., 2010). En 2005 se producen los primeros sueros para países africanos y poco después un estudio clínico efectuado en Nigeria confirma su eficacia y seguridad en pacientes (Abubakar et al., 2010). A partir de este logro, el ICP produce antiveneno, no solo para Nigeria, sino para otros países de ese continente: la lista donde el suero ha sido empleado incluye: Camerún, Costa de Marfil, Chad, Etiopía, Guinea-Bissáu, Kenia, Malawi, Mali, Níger, República Centroafricana, Sudán del Sur, Tanzania. Otras iniciativas han surgido para desarrollos similares en países como Papua-Nueva Guinea, así como proyectos para transferir nuestra tecnología y experiencia a otros países, como Sri Lanka e India.

Al tratarse de faunas ofídicas muy distintas a la nuestra y que, por consiguiente, producen envenenamientos diferentes, los desarrollos para esas otras regiones del mundo requieren un suministro de los venenos de especies involucradas, así como su caracterización bioquímica y de los efectos farmacológicos que producen sus toxinas. 
Además, una vez desarrollado el producto (antiveneno) se requiere de la realización de pruebas que confirmen su capacidad neutralizante sobre esos efectos. De esta manera, la participación en estos proyectos de desarrollo internacional ha permitido el establecimiento de una batería de pruebas que evalúan el desempeño de antivenenos y que puede ser aplicados tanto a los producidos en el ICP, como a otros que sean de interés (Sánchez et al., 2015; Rivel et al., 2016).

\section{Sistemática e historia natural de serpientes}

Como hemos visto, la materia prima para la elaboración del suero antiofídico es el veneno de serpientes, razón por la que el serpentario fue una de las primeras unidades creadas en el Instituto. Mantener serpientes en cautiverio requiere de conocimiento sobre su taxonomía, requerimientos ambientales y fisiológicos, comportamiento, reproducción y aspectos básicos de ecología, incluyendo enemigos naturales, parásitos y dieta. A lo largo de estos cincuenta años estos temas han sido estudiados por el personal del instituto.

El recibir serpientes de todo el país fue clave para recopilar información sobre su distribución (Taylor et al., 1974), así como aspectos medulares de su historia natural (Campbell y Solórzano, 1992). Muchos de los trabajos abordados durante los primeros años permitieron describir los ciclos reproductivos de víboras y elápidos del país (Solórzano y Cerdas, 1988a,b). Entre esos estudios resalta el trabajo de Solórzano y Cerdas (1989) sobre la biología reproductiva de la terciopelo Bothrops asper, la serpiente más importante desde el punto de vista médico en Costa Rica, responsable de más del $70 \%$ de los envenenamientos en la región. Este estudio ejemplifica muy bien como influencian los patrones de lluvia en distintos momentos de la recrudescencia gonadal en machos y hembras y es un referente para entender los ciclos de otras especies de serpientes en esta región. El trabajo de la terciopelo además inspiro estudios posteriores sobre otros aspectos de la biología de esta víbora. Entre ellos, destacan los realizados junto al Dr. Dennis Wasko, entonces científico de la Universidad de Miami, para determinar el ámbito de hogar (Wasko y Sasa, 2009), movimientos y selección de hábitat en esa especie (Wasko y Sasa, 2012). También, se evaluó el efecto que tiene la disponibilidad de presas en esas variables (Wasko et al., 2014). Estos esfuerzos han hecho de la terciopelo una de las especies venenosas más estudiadas del Neotrópico (Sasa et al., 2009).
Estudios de taxonomía y sistemática de serpientes de Costa Rica han sido una constante en el quehacer del instituto y han permitido enriquecer el catálogo de la diversidad ofídica del país. Entre las especies descritas como nuevos taxones en el instituto o con material aportado por el instituto se cuentan los siguientes: Agkistrodon howardgloydi (Bolaños y Montero, 1970), Lachesis melanocephala (Solórzano y Cerdas, 1986), Bothriechis supraciliaris (Solórzano et al., 1998), Porthidium volcanicum (Solórzano, 1994), Porthidium porrasi (Lamar y Sasa, 2003), y Bothriechis nubestris (Doan et al., 2018) (Fig. 11). Los trabajos en sistemática de serpientes se han abordado a partir de una sólida colaboración con Todd Castoe y otros investigadores de la Universidad de Texas en Arlington. A partir de caracteres moleculares, estos trabajos reconstruyen las relaciones evolutivas (filogenias) entre especies o grupos de serpientes que habitan en la región Mesoamericana (Castoe et al., 2005; 2009). A partir de estas repercusiones se evalúan hipótesis sobre la importancia de eventos cladogénicos para explicar patrones biogeográficos en la región (Castoe et al., 2009) Además, estas reconstrucciones permiten esclarecer relaciones que eventualmente derivan en propuestas taxonómicas. Las descripciones de especies crípticas, como Porthidium porrasi, Bothriechis nubestris, y B. supraciliares, mencionadas anteriormente son un buen ejemplo de ello.
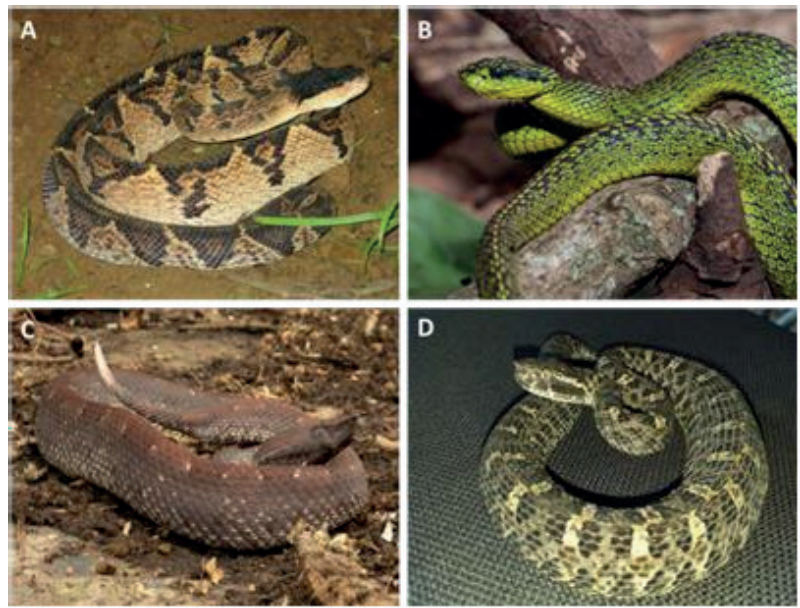

Figura 11. Especies de serpientes descritas por investigadores del ICP. (A) Lachesis melanocephala. (B) Porthidium volcanicum. (C) Porthidium porrasi. (D) Bothriechis nubestris. Fuente: fotografías cortesía de A. Solórzano, A. Vega y C. Bravo. 


\section{Abordaje integral, multidisciplinario y trans- disciplinario}

El abordar un problema desde distintos ángulos suele llevar a una mejor comprensión de este y - posiblementea soluciones más permanentes. En el caso del accidente ofídico, se trata de un problema multidimensional, que involucra no solo la especie de serpiente, los componentes de su veneno o los efectos que estos producen en el cuerpo del paciente, sino que además incluye consideraciones sobre su epidemiología, disponibilidad y efectividad del tratamiento, accesibilidad a este, políticas de salud pública, medidas de prevención, entre otros. Por lo que acometer este problema de forma efectiva requiere de una estrategia integral que no descuide esas múltiples dimensiones que lo integran.

El colectivo científico del ICP ha sabido seguir una estrategia integral en su abordaje del accidente ofídico, actuando sobre distintos frentes. Por un lado, la fabricación del producto terapéutico se acompaña de un sólido programa de investigación en múltiples temas. Por otro lado, la generación de conocimiento retroalimenta la producción de antivenenos y sustenta las actividades dirigidas a la capacitación, prevención y promoción de políticas que se realizan desde el instituto. Estas acciones se enmarcan en el programa de extensión o acción social del ICP, y es la forma como se retribuye a la sociedad los conocimientos generados. Las actividades de acción social son reconocidas como eje fundamental de la UCR desde el III Congreso Universitario (1971-1972) (Gutiérrez, 2019).

El entender mejor la fisiopatología del envenenamiento es información que ha sido trasladada al personal de salud del país y de la región mediante actividades de educación continua, lo que a su vez ha permitido actualizar y homogeneizar tratamientos. Los estudios epidemiológicos permiten identificar las regiones del país que requieren atención en la distribución de los centros de salud y distribución de antivenenos y han contribuido en evaluar el papel que han jugado los EBAIS en agilizar la atención del envenenamiento en zonas rurales (Hansson et al., 2013). Otro ejemplo son las capacitaciones a cuerpos de socorro sobre captura y manejo de serpientes y otros reptiles peligrosos. Un altísimo porcentaje de las llamadas que ingresan al servicio de emergencia 911 refieren a situaciones generadas por encuentros con animales y por mandato de estos, y deben ser atendidas. La capacitación práctica en el manejo humanitario de estos animales es una labor que es llevada a cabo por el ICP (Fig. 12), y gracias a los es- fuerzos del biólogo Fabián Bonilla se ha logrado disponer del Laboratorio de Investigaciones en Animales Peligrosos, un módulo que mantiene animales para ser usados en dichas prácticas.

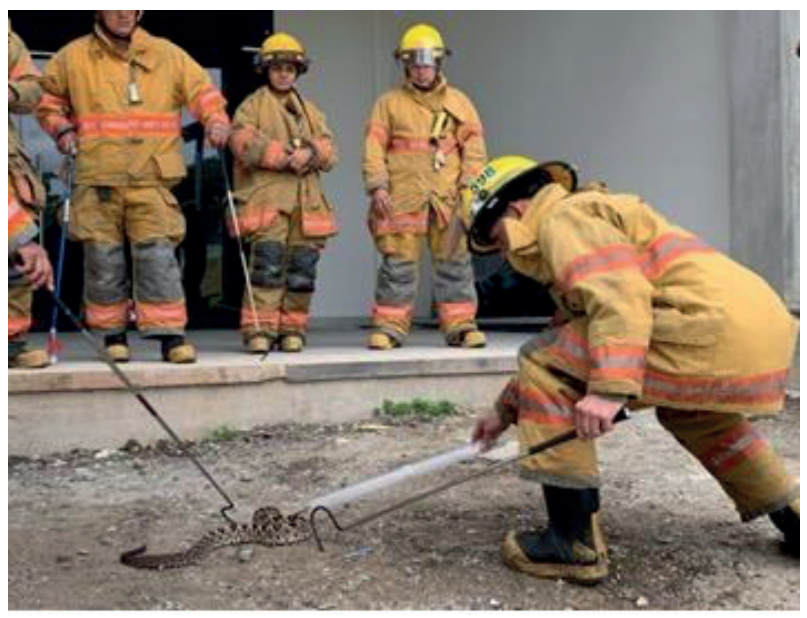

Figura 12. Capacitación al Cuerpo de Bomberos en el manejo humanitario de serpientes venenosas. Fuente: fotografía cortesía F. Bonilla.

Un aspecto que suele pasar desapercibido, pero que está siendo incorporado poco a poco por el colectivo del ICP, es el de la transdisciplinariedad, este es un concepto que tiene distintas acepciones, pero aquí se refiere a la estrategia de investigación que atraviesa campos disciplinarios para crear enfoques holísticos.

La complejidad del accidente ofídico y sus múltiples dimensiones, así como la pluralidad de acciones realizadas en el ICP, obligan a valorar los fenómenos interconectados. Situaciones físicas, biológicas, clínicas, sociales y psicológicas interactúan recíprocamente, lo que exige formas de valoración desde perspectivas más amplias para poder interpretar la realidad. Un ejemplo de cómo la transdisciplinariedad enriquece las contribuciones científicas se puede apreciar en la publicación reciente de la socióloga Jazmín Arias y el Dr. José María Gutiérrez sobre las consecuencias sociales del envenenamiento ofídico en Costa Rica (Arias y Gutiérrez, 2019). A pesar de la vasta producción científica sobre el veneno y su patología, hay una escasez de estudios cualitativos centrados en las circunstancias y consecuencias de los envenenamientos por mordedura de serpiente más allá del tratamiento, particularmente, en entornos rurales empobrecidos dedicados a actividades agrícolas. En este estudio, metodologías de análisis cualitativos comunes en ciencias sociales fueron 
empleadas para extraer información sobre la situación postratamiento y las secuelas sociales del envenenamiento. A partir de entrevistas en profundidad a afectados en el Pacifico Sur del país, se identificaron múltiples y graves consecuencias de los envenenamientos en los trabajadores rurales y sus familias. Los resultados demuestran que no es suficiente brindar una buena atención médica a estos pacientes, ya que muchos de ellos sufren secuelas psicológicas que muchas veces pasan desapercibidas para el sistema de salud pública. Esto es particularmente cierto en casos de trabajadores independientes en la informalidad, situación común entre peones agrícolas, precisamente, el grupo más afectado por mordeduras. Estas consecuencias deben ser atendidas por instituciones públicas y organizaciones de la sociedad civil. Así mismo, las personas afectadas sufren dificultades como consecuencia del envenenamiento por mordedura de serpiente que alimenta un círculo vicioso de pobreza en comunidades rurales, un tema que también merece atención urgente. A raíz de este estudio, actualmente, se promueve que el Instituto Nacional de Seguros apoye la rehabilitación y seguro a pacientes que, al no encontrarse asegurados, históricamente han sido excluidos de ellos.

\section{ICP en los tiempos del COVID-19}

La pandemia de Covid-19 ha afectado el país desde marzo del 2020 y diversas instituciones han reaccionado al llamado del Gobierno central para establecer un frente común para enfrentarla. La enorme experiencia del ICP en la producción de productos inmunobiológicos, así como su sólido programa de investigación basado en la colaboración con grupos nacionales e internacionales, en conjunto con su profundo sentimiento de servicio hicieron del instituto uno de los actores más notables de este frente común. Los esfuerzos por encontrar soluciones terapéuticas iniciaron con el Dr. Alberto Alape y todo el grupo de la División Industrial del ICP, liderados por el Dr. Guillermo León.

Al tiempo que estas líneas son escritas, no existe todavía un tratamiento específico aprobado para la infección por el nuevo coronavirus, pero una apuesta posible es neutralizarlo o inducir una respuesta de citotoxicidad dependiente de anticuerpos, que permita la remoción de los agentes virales circulantes. A partir de experiencias en el tratamiento de pacientes infectados con otros virus respiratorios se sabe que varias opciones de inmunoterapia pasiva con anticuerpos pueden combatirlas. Entre ellas, el uso de plasma de pacientes convalecientes o de anticuer- pos purificados de ese plasma, el uso de anticuerpos monoclonales contra las proteínas del virus, y el empleo de anticuerpos policlonales producidos en animales, a través de la inmunización con algunas proteínas virales.

Por lo tanto, es importante mencionar que estas opciones terapéuticas difieren en la relación eficacia/seguridad, principalmente, debido al riesgo potencial de desarrollar reacciones adversas. Así, las preparaciones de inmunoglobulinas purificadas son una opción más segura y con mayor actividad que simplemente aplicar el plasma convaleciente. Sin embargo, en ambos casos hay un riesgo de desarrollar enfermedades causadas por otros virus presentes en la sangre de los donadores. De manera que producir anticuerpos monoclonales tiene altos costos asociados y la selección de los posibles anticuerpos neutralizantes es un proceso que consume mucho tiempo, por lo que la utilización de policlonales podría ser una opción de menor costo.

La propuesta del Clodomiro Picado fue en estos dos abordajes: la purificación de anticuerpos de plasma convaleciente, que desgraciadamente aún no se ha implementado por falta de volumen de plasma, y la producción de anticuerpos policlonales equinos (Instituto Clodomiro Picado, 2020). Esta última opción fue la desarrollada en el ICP. Un primer ensayo clínico en pacientes diagnosticados con Covid-19 que ingresaron a hospitales de la Caja Costarricense de Seguro Social ha mostrado que estos tratamientos son seguros, al encontrarse una baja tasa de reacciones adversas, similar a la observada al aplicar los antivenenos producidos por el ICP. Estos resultados son esperanzadores, y actualmente se trabaja en un ensayo clínico dirigido a determinar dosis efectivas para el tratamiento de estos pacientes.

\section{Conclusiones}

El accidente ofídico es un importante problema de salud que posee múltiples dimensiones, por lo que su abordaje debe ser integral. A partir de una iniciativa país, el problema del ofidismo en Costa Rica es tratado desde una universidad pública en la figura del Instituto Clodomiro Picado. La búsqueda de soluciones al problema local ha tenido importantes repercusiones a nivel regional y global, por lo que la labor del ICP es considerada como un ejemplo exitoso que ha logrado metas de gran trascendencia en los planos científico, productivo y de extensión. 


\section{Agradecimientos}

Agradecemos a José María Gutiérrez y Bruno Lomonte por proveer detalles a la historia del Instituto, así como a Alejandro Solórzano, Fabián Bonilla, Andrés Vega y Carlos Bravo por el permiso de uso de sus fotografías.

\section{Referencias}

Abubakar, I.S., Abubakar, S.B., Habib, A.G., Nasidi, A., Durfa, N., Yusuf, P.O., Larnyang, S., Garnvwa, J., Sokomba, E., Salako, L., Theakston, R.D.G., Juszczak, E., Alder, N., Warrell, D. A. (2010). Randomized controlled double-blind non-inferiority trial of two antivenoms for saw- scaled or carpet viper (Echis ocellatus) envenoming in Nigeria. PLoS Neglected Tropical Diseases, 4(7), e767.

Altieri, M.A. (2000). Multifunctional dimensions of ecologically-based agriculture in Latin America. The International Journal of Sustainable Development \& World Ecology, 7(1), 62-75.

Arias-Rodríguez, J., \& Gutiérrez, J.M. (2020). Circumstances and consequences of snakebite envenomings: a qualitative study in South-Eastern Costa Rica. Toxins, 12(1), 45.

Arroyo, O., Rojas, G., \& Gutiérrez, J.M. (1999). Envenenamiento por mordedura de serpiente en Costa Rica en 1996: Epidemiología y consideraciones clínicas. Acta médica costarricense, 41(4).

Arroyo, O. \& Cerdas, L. (1984) Estudio ultraestructural de las alteraciones locales inducidas en ratón blanco por el veneno de Bothrops picadoi de Costa Rica. Toxicon 22, 301-305.

Bolaños, R. \& Montero, J.R. (1970) Agkistrodon bilineatus Gunther from Costa Rica. Revista de Biología Tropical 16, 277-279.

Campbell, J.A., \& Lamar, W.W. (2004). The Venomous Reptiles of the Western Hemisphere. Ithaca, USA: Cornell University Press.

Campbell J.A., \& A. Solórzano. (1992). The distribution, variation, and natural history of the Middle American montane pitviper, Porthidium godmani. Pp. 223-250. In J. A. Campbell and

E.D. Brodie, Jr. (Eds.), Biology of the Pitvipers. Selva, Tyler, Texas.
Castoe, T.A., M. Sasa, \& Parkinson, C. L. (2005). Modeling nucleotide evolution at the mesoscale: The phylogeny of the Neotropical pitvipers of the Porthidium group (Viperidae: Crotalinae). Molecular Phylogenetics and Evolution 37, 841-898.

Castoe, T.A., Daza, J.M., Smith, E.N., Sasa, M., Kuch, U., Campbell, J.A., Chippindale, P.T., \& Pakinson, C.L. (2009). Comparative phylogeography of pitvipers suggest a consensus of ancient Middle American highland biogeography. Journal of Biogeography 36, 88-103.

Cerdas, L. \& Lomonte, B. (1982). Estudio de la capacidad ofiófaga y la resistencia de la zopilota (Clelia clelia, Colubridae) de Costa Rica a los venenos de serpiente. Toxicon 20, 936-939.

Chippaux, J.P. (2017) Incidence and mortality due to snakebite in the Americas. PLoS Negl. Trop. Dis. 11(6): e0005662.

Díaz, C., Gutiérrez, J.M. \& Lomonte, B. (1992) Isolation and characterization of basic myotoxic phospholipases A2 from Bothrops godmani (Godman's pit viper) snake venom. Archives of Biochemistry and Biophysics 298, 135-142.

Díaz, C., Alape, A., Lomonte, B., Olamendi, T., \& Gutiérrez, J.M. (1994) Cleavage of the NH2- terminal octapeptide of Bothrops asper myotoxic lysine- 49 phospholipase A2 reduces its membrane-destabilizing effect. Archives of Biochemistry and Biophysics 312, 336-339.

Díaz C, Rivera, J., Lomonte, B., Bonilla, F., Diego-García, E., Camacho, E., Tytgat, J., Sasa M. (2019) Venom characterization of the bark scorpion Centruroides edwardsii (Gervais 1843): composition, biochemical activities and in vivo toxicity for potential prey. Toxicon 171, 7-19.

Doan, T.M., Mason, A.J., Castoe, T.A., Sasa, M., \& Parkinson, C.L. (2016). A cryptic

palm-viper species (Squamata: Biperidae: Bothriechis) from the Costa Rican highlands, with notes on the variation within B. nigroviridis. Zootaxa 4138(2), 271-290.

Estrada, R., Robles, A., Alvarado, J., Rojas, E., González, N., Segura, E. \& Gutiérrez, J.M. (1991). Development of antibody response and clinical and hematological alterations in horses immunized with snake venoms for the production of antivenom in 
Costa Rica. Memorias do Instituto Butantan 53, 181-190.

Estrada, R., Chaves, F., Robles, A., Rojas, E., Segura, E. \& Gutiérrez, J.M. (1992) Valores hematológicos y de enzimas séricas en caballos inoculados con venenos de serpientes para la producción de antivenenos en Costa Rica. Revista de Biología Tropical 40, 95-99.

Espinoza, A.M., León, P., Macaya, G., Fuentes, A.L. \& Gutiérrez, J.M. (1980) Estructura y función de los cromosomas plumulados. Revista de Biología Tropical 28, 209-226.

Flores-Díaz, M., Barquero-Calvo, E., Ramírez, M., \& Alape-Girón, A. (2016). Role of Clostridium perfringens toxins in necrotic enteritis in poultry. Springer Science\&Business Media B.V. P. Gopalakrishnakone et al. (eds.), Microbial Toxins, Toxinology, DOI 10.1007/978-94-007-6725-6_15-1.

Gené, J.A., Gómez, M. \& Cerdas, L. (1986). Estudio sobre la estabilidad de la actividad neutralizante del suero antiofídico contra veneno de terciopelo ( $\mathrm{BO}$ throps asper). Revista Costarricense de Ciencias Médicas 7, 3-9.

Fan, H.W., Vigilato, M.A.N., Pompei, J.C.A., Gutiérrez, J.M. \& Red RELAPA. (2019) Situación de los laboratorios públicos productores de antivenenos en América Latina. Revista Panameña Salud Publica, 43: e92. https://doi.org/10.26633/RPSP.2019.92

Fernández, J., Vargas-Vargas,N., Pla, D., Sasa, M., ReySuárez, R., Sanz, L., Gutiérrez, J.M., Calvete, J.J., $\&$ Lomonte, B. (2015). Snake venomics of Micrurus alleni and Micrurus mosquitensis from the Caribbean region of Costa Rica reveals two divergent compositional patterns in New World elapids. Toxicon 107:217-233.

Gutiérrez, J.M. (2002). Comprendiendo los venenos de serpientes: 50 años de investigaciones en América Latina. Revista de biología tropical, 50(2), 377394.

Gutiérrez, J.M. (2010). Los orígenes del Instituto Clodomiro Picado. Facultad de Microbiología, Universidad de Costa Rica. 60 p.

Gutiérrez, J.M. (2019a). La atención del problema de los envenenamientos por mordeduras de serpientes en Costa Rica: un proyecto nacional con proyección global. Pp. 169-189. Reflexiones desde la acade- mia: universidad, ciencia y sociedad. Arlequín, San José, 189 pp.

Gutiérrez, J.M. (2019b) Global availability of antivenoms: The relevance of public manufacturing laboratories. Toxins 11: 5. 2-13

Gutiérrez, J.M. \& Bolaños, R. (1981) Polimorfismo cromosómico intraespecífico en la serpiente coral $\mathrm{Mi}$ crurus nigrocinctus (Ophidia: Elapidae). Revista de Biología Tropical 29, 115-122.

Gutiérrez, J.M. \& Chaves, F. (1980) Efectos proteolítico, hemorrágico y mionecrótico de los venenos de serpientes costarricenses de los géneros Bothrops, Crotalus y Lachesis. Toxicon 18, 315-321.

Gutiérrez, J.M. \& Lomonte, B. (1997): Phospholipase A2 myotoxins from Bothrops snake venoms. In: Venom Phospholipases A2: Structure, Function and Mechanism, pp 321-352 (Kini, R.M., Ed.). Chichester, John Wiley \& Sons

Gutiérrez, J.M. \& Nájera, J.M. (1989). Clodomiro Picado y sus años de formación científica. Historia de la Ciencia y la tecnología; el avance de una disciplina, 1-11.

Gutiérrez, J.M. \& Pereañez, J.A. (2016) The need for an integrated approach in confronting snakebite envenoming in Latin America: The relevance of endogenous scientific and technological research. Vitae (Colombia) 23, 103-105.

Gutiérrez, J.M., \& Rojas-Céspedes, G. (1999). Instituto Clodomiro Picado: Ciencia y Tecnología Endógenas en la Solución de un Problema de la Salud Pública en Centroamérica.Interciencia, 24(3), 182-186.

Gutiérrez, J.M., Taylor, R., \& Bolaños, R. (1979). Cariotipos de diez especies de serpientes costarricenses de la familia Viperidae. Revista de Biología Tropical 27, 309-319.

Gutiérrez, J.M., Avila, C., Rojas, E., \& Cerdas, L. (1988a) An alternative in vitro method for testing the potency of the polyvalent antivenom produced in Costa Rica. Toxicon 26, 411-413.

Gutiérrez, J.M., Chaves, F., Rojas, E., Elizondo, J., Avila, C., \& Cerdas, L. (1988b) Production of monovalent anti-Bothrops asper antivenom: development of immune response in horses and neutralizing ability. Revista de Biología Tropical 36, 511-517. 
Gutiérrez, J.M., Theakston R.D.G., Warrell, D.A. (2006). Confronting the neglected problem of snake bite envenoming: the need for a global partnership. PLoS Med., 6: e150.

Gutiérrez, J.M., Burnouf, T., Harrison, R.A., Calvete, J.J., Brown, N., Jensen, S.D. (2015). A Call for Incorporating Social Research in the Global Struggle against Snakebite. PLoS Negl Trop Dis 9(9): e0003960. doi:10.1371/journal.pntd.0003960

Hansson, E., Sasa, M., Mattisson, K., Robles, A., \& Gutiérrez, J.M. (2013). Using geographical information systems to identify populations in need of improved accessibility to antivenom treatment for snakebite envenoming in Costa Rica. PLoS Negl Trop Dis 7(1): e2009. doi:10.1371/journal. pntd.0002009.

Instituto Clodomiro Picado. (2020). Producción de formulaciones terapéuticas de inmunoglobulinas anti-SARS-CoV-2 purificadas a partir de plasma de pacientes convalescientes o equinos inmunizados con proteínas virales recombinantes. Revista Médica de Costa Rica 85, 629 :81-87.

Kasturiratne, A., Wickremasinghe, A.R., de Silva, N., Gunawardena, N.K., Pathmeswaran, A., Premaratna, R., Savioli, L., Laloo, D.G., \& de Silva, H.J. (2008). The global burden of snakebite: A literature analysis and modelling based on regional estimates of envenoming and deaths. PLoS Med. 2008, 5 .

Katz, J.S., \& Martin, B.R. (1997). What is research collaboration? Research policy, 26, 1-18.

Lamar, W. W., \& Sasa, M. (2003). A new species of hognose pitviper genus Porthidium from the southwestern Pacific of Costa Rica (Serpentes: Viperidae). Revista de Biología Tropical. 51, 797- 804.

Lomonte, B. (2012). Investigación científica y tecnológica en el Instituto Clodomiro Picado: una perspectiva bibliométrica de cuatro décadas (1970-2010). Interciencia, 37(6), 424-430.

Lomonte, B., \& Calvete, J.J. (2017). Strategies in 'snake venomics' aiming at an integrative view of compositional, functional, and immunological characteristics of venoms. Journal of Venomous Animals and Toxins including Tropical Diseases, 23, 26.

Lomonte, B., \& Gutiérrez, J.M. (1983). La actividad proteolítica de los venenos de serpientes de Costa
Rica sobre la caseína. Revista de Biología Tropical 31, 37-40.

Lomonte, B., Cerdas, L., Gené, J.A. \& Gutiérrez, J.M. (1982). Neutralization of local effects of the terciopelo (Bothrops asper) venom by blood serum of the colubrid snake Clelia clelia. Toxicon 20, 571-579.

Lomonte, B., Cerdas, L., Solórzano, A. \& Martínez, S. (1989). El suero de neonatos de Clelia Clelia (serpientes Colubridae) neutraliza la acción hemorrágica del veneno de Bothrops asper (Serpentes, Viperidae). Revista de Biología Tropical 38, 325326.

Lomonte, B., Fernandez, J., Sanz, L., Angulo,Y., Sasa, M., Gutiérrez, J.M., \& Calvete, J.J. (2014). Venomous snakes of Costa Rica: Biological and medical implications of their venom proteomic profiles analyzed through the strategy of snake venomics. Journal of Proteomics, 105, 323-339.

Lomonte, B., Rey-Suárez, P., Fernández, J., Sasa, M., Pla, D., Vargas, N., Bérnard-Valle, M., Sanz, L., Correa-Neto, C., Núñez, V., Alape-Girón, A., Alagón, A., Gutiérrez, J.M., \& Calvete.

J.J. (2016). Venoms of Micrurus coral snakes: evolutionary trends in compositional patterns emerging from proteomics analyses. Toxicon 122, 7-25.

Martínez, S., \& Cerdas, L. (1986) Captive reproduction of the mussurana, Clelia clelia (Daudin) from Costa Rica. Herpetological Reviews 17, 12.

Picado T., C. 1931. Serpientes Venenosas de Costa Rica. Imprenta Alsina (Sauter, Arias \& Co.), San Jose, Costa Rica.

Rivel, M., Solano, D., Herrera, M., Vargas, M., Villalta, M., Segura, A., Arias, A.S., León, G., \& Gutiérrez, J.M. (2016). Pathogenesis of dermonecrosis induced by venom of the spitting cobra, Naja nigricollis: an experimental study in mice. Toxicon 119: 171-179.

Rojas-Azofeifa, D., Sasa, M., Lomonte, B., Diego-García, E., Ortiz, N., Bonilla, F., Murillo, F., Tytgat, J., \& Díaz, C. (2019). Biochemical characterization of the venom of Central American scorpion Didymocentrus krausi Francke, 1978 (Diplocentridae) and its toxic effects in vivo and in vitro. Comparative Biochemistry and Physiology - Part C: Toxicology \& Pharmacology 217, 54- 67. 
Rucavado, A., Borkow, G., Ovadia, M. \& Gutiérrez, J.M. (1995a). Immunological studies on $\mathrm{BaH} 1$ and $\mathrm{BaP} 1$, two hemorrhagic metalloproteinases from the venom of the snake Bothrops asper. Toxicon 33, 1103-1106.

Rucavado, A., Lomonte, B., Ovadia, M. \& Gutiérrez, J.M. (1995b). Local tissue damage induced by BaP1, a metalloproteinase isolated from Bothrops asper (Terciopelo) snake venom. Experimental and Molecular Pathology 63, 186-199.

Sánchez, L.V., Pla, D., Herrera, M., Chippaux, J.P., Calvete, J.J. \& Gutiérrez, J.M. (2015). Evaluation of the preclinical efficacy of four antivenoms, distributed in sub-Saharan Africa, to neutralize the venom of the carpet viper, Echis ocellatus, from Mali, Cameroon, and Nigeria. Toxicon 106: 97107

Sasa, M., \& Segura-Cano, S.E. (2020). New insights into snakebite epidemiology in Costa Rica: A retrospective evaluation of medical records. Toxicon: $X$, 7, 100055 .

Segura, A., Villalta, M., Herrera, M., León, G., Harrison, R., Durfa, N., Nasidi, A., Calvete, J.J., Theakston, R.D.G., Warrell, D.A., \& Gutiérrez, J. M. (2010). Preclinical assessment of the efficacy of a new antivenom (EchiTAb-Plus-ICP $®$ ) for the treatment of viper envenoming in sub-Saharan Africa. Toxicon, 55(2-3), 369-374.

Solórzano, A. (1994). Una nueva especie de serpiente venenosa terrestre del género Porthidium (Serpentes: Viperidae), del Suroeste de Costa Rica. Revista de biología tropical, 695-701.

Solórzano, A. \& Cerdas, L. (1984). Confirmación de la presencia de Micrurus clarcki Schmidt (Elapidae) en Costa Rica. Revista de Biología Tropical 32, 317-318.

Solórzano, A. \& Cerdas, L. (1986). A new subspecies of the bushmaster, Lachesis muta, from southeastern Costa Rica. Journal of Herpetology 20, 463-466.

Solórzano, A., Gómez, L. D., Monge-Nájera, J., \& Crother, B.I. (1998). Redescription and validation of Bothriechis supraciliaris (Serpentes: Viperidae). Revista de biología tropical, 46, 453-462.

Solórzano, A., Gutiérrez, J.M. \& Cerdas, L. (1987). Bothrops ophryomegas Bocourt (Serpentes: Viperidae) en Costa Rica: Distribución, lepidosis, variación sexual y cariotipo. Revista de Biología Tropical 36, 187-190.

Solórzano, A. \& Cerdas, L. (1988a) Biología reproductiva de la cascabel centroamericana Crotalus durissus durissus (Serpentes: Viperidae) en Costa Rica. Revista de Biología Tropical 36, 221-226.

Solórzano, A. \& Cerdas, L. (1988)b Ciclos reproductivos de la serpiente coral Micrurus nigrocinctus (Serpentes: Elapidae) en Costa Rica. Revista de Biología Tropical 36, 235-239.

Solórzano, A. \& Cerdas, L. (1989) Reproductive biology and distribution of the terciopelo,

Bothrops asper Garman (Serpentes: Viperidae) in Costa Rica. Herpetologica 45, 444-450.

Wasko, D.K. \& Sasa, M. (2009). Activity patterns of a Neotropical ambush predator: Spatial Ecology of the fer-de-lance (Bothrops asper, Serpentes: Viperidae) in Costa Rica. Biotropica 41(2):241-249.

Wasko, D.K. \& Sasa, M. (2012). Food resources influence spatial ecology, habitat selection, and foraging behavior in an ambush-hunting snake (Viperdiae: Bothrops asper): an experimental study. Zoology 115:179-187.

Wasko, D.K., Bonilla, F., \& Sasa, M. (2014). Behavioral responses to snake cues by three species of rodents. Journal of Zoology 292:142-150.

Williams, D.J., Gutiérrez, J.M., Harrison, R., Warrell, D.A., White, J., Winkel, K.D., \& Gopalakrishnakone, P. (2010). The Global Snake Bite Initiative: An antidote for snake bite. Lancet, 375, 89-91.

Williams, D.J., Faiz, M.A., Abela-Ridder, B., Ainsworth, S., Bulfone, T.C., Nickerson, A. D., Habib, A.G., Junghanss, T., Fan, H.W., Turner, M., Harrison, R.A., \& Warrell, D.A. (2019). Strategy for a globally coordinated response to a priority neglected tropical disease: snakebite envenoming. PLoS Neglected Trop. Dis. 13 (2), e0007059.

World Health Organization. (2019). Snakebite Envenoming. A Strategy for Prevention and Vontrol. WHO, Geneva, p. 50. Available at: https://www. who.int/snakebites/re sources/9789241515641/ en/. (Accessed 16 February 2020).

Taylor, R., Flores, A., Flores, G., \& Bolaños, R. (1974) Geographical distribution of Viperidae, Elapidae 
and Hydrophiidae in Costa Rica. Revista de Biología Tropical 21, 383-397.

Vargas, M., Segura, A., Wu, Y. W., Herrera, M., Chou, M. L., Villalta, M., G. León \& Burnouf, T. (2015). Human plasma-derived immunoglobulin $\mathrm{G}$ fractionated by an aqueous two-phase system, caprylic acid precipitation, and membrane chromatography has a high purity level and is free of detectable in vitro thrombogenic activity. Vox sanguinis, 108(2), 169-177.
Zeledón, R. (1999). Dr. Clodomiro Picado Twight. Prociencia. Consejo Nacional Investigacion en Ciencia y Tecnología, Costa Rica. 4 pp.

Zúñiga-Chaves I., Flores-Díaz M., \& Alape-Girón A. (2016). Insights into the Evolution of Bacterial Sphingomyelinases and Phospholipases Associated to Virulence. Springer Science+Business Media B.V. P. Gopalakrishnakone et al. (eds.), Microbial Toxins, Toxinology, DOI 10.1007/978-94007-6725-6_33-1 